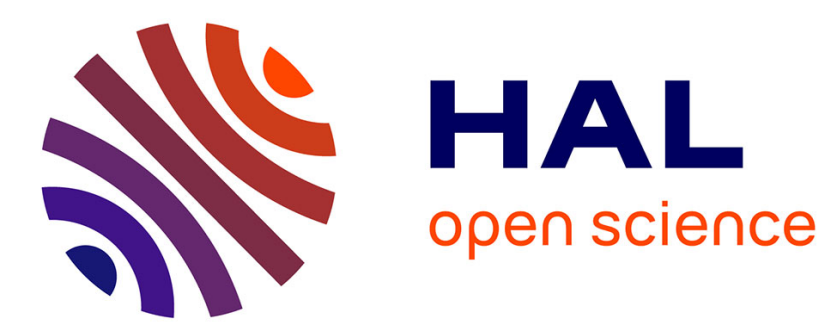

\title{
The European growth synchronization through crises and structural changes
}

\author{
Merih Uctum, Remzi Uctum, Chu-Ping C Vijverberg
}

\section{To cite this version:}

Merih Uctum, Remzi Uctum, Chu-Ping C Vijverberg. The European growth synchronization through crises and structural changes. Studies in Nonlinear Dynamics and Econometrics, 2021, 25 (1), pp.1-17. 10.1515/snde-2018-0097 . hal-03319011

\section{HAL Id: hal-03319011 \\ https://hal.science/hal-03319011}

Submitted on 11 Aug 2021

HAL is a multi-disciplinary open access archive for the deposit and dissemination of scientific research documents, whether they are published or not. The documents may come from teaching and research institutions in France or abroad, or from public or private research centers.
L'archive ouverte pluridisciplinaire HAL, est destinée au dépôt et à la diffusion de documents scientifiques de niveau recherche, publiés ou non, émanant des établissements d'enseignement et de recherche français ou étrangers, des laboratoires publics ou privés. 


\title{
The European Growth Synchronization through Crises and Structural Changes
}

\author{
by \\ Merih Uctum $^{\dagger}$, Remzi Uctum ${ }^{\dagger \dagger}$, Chu-Ping C. Vijverberg ${ }^{\ddagger}$ \\ $†$ Corresponding author, The Graduate Center and Brooklyn College, City University of New York \\ $\dagger \dagger$ Centre National de la Recherche Scientifique, Université Paris Ouest Nanterre la Défense \\ $\ddagger$ College of Staten Island and the Graduate Center, City University of New York
}

\begin{abstract}
In light of several economic and financial crises and institutional changes experienced by the European countries, we examine whether these economies achieved synchronization of their business cycles and fostered synchronization of their growth rates. Controlling for reverse causality, we conduct multiple endogenous break tests and find (i) several endogenous break dates that correspond to idiosyncratic shocks affecting individual countries, major shocks in international arena but not the adoption of the euro, suggesting that the convergence process has been nonlinear for a number of countries and that studies imposing break dates exogenously, such as the launch of euro, may lead to biased conclusions; (ii) while output growth was increasingly synchronized for some countries, integration occurred in an asymmetric way and it didn't change or didn't occur for others despite being in the same common currency area (iii) convergence has been prevalent among the non-Eurozone economies in our sample.
\end{abstract}

Key words: Convergence, growth synchronization, euro, crises, structural breaks JEL Classification number: E3, F4, F6

DOI: 10.1515/snde-2018-0097 


\section{Introduction}

The 2008 U.S. financial crisis that caused a global recession also pushed many European countries, in particular those in the periphery, into a stubborn recession which transformed into an anemic growth in most cases and to populist movements. At a stage where the integrity of the European Union is at stake, the crisis and its fallouts are seen as an indictment of the European Monetary Union for failing to generate convergence among its members and to spur European integration. Convergence is crucial for the conduct of the single monetary policy where members do not have recourse to fiscal transfer mechanisms nor currency adjustments. Yet several recent studies reveal a troublesome trend in "de-synchronization" with the core after the financial crisis. In this paper we examine whether the long process of European unification, which culminated in the monetary union and a single currency, led to increased synchronization of output growth for member countries and whether the increased synchronization was associated with the single currency, idiosyncratic policies, reforms or global shocks.

The idea of a unified Europe started in the 1950s with the establishment of the European trade area with the European Coal and Steel Community, continued through the 1970s driven by the Franco-German "locomotive," and culminated in the European Monetary Union. Yet, the birth of the monetary union occurred in the midst of intense controversy about whether the Eurozone was ready to become a currency union since it was not satisfying the original criteria of the Optimal Currency Area ${ }^{1}$. Subsequently, studies of currency unions introduced by Rose (2000) and Frankel and Rose (1996, 1998) showed a significantly deepened trade integration among member countries of a monetary union. The implication is that the Optimal Currency Area criteria can be satisfied if unification leads to trade integration and income convergence.

The endogenous business cycle synchronization argument draws on two linkages: currency union increases trade and increased trade leads to synchronization of business cycles. For the second linkage, two opposite views prevail. The European Commission's view was that higher trade integration would trigger synchronization of business cycles. Krugman (1993) cautioned against this view by arguing that higher trade integration leads to specialization, regional concentration of activity and hence to asymmetric shocks, which reduces

\footnotetext{
${ }^{1}$ Mundell (1961), McKinnon (1963) and Kenen (1969) argued that if a geographical region exhibits high capital and labor mobility, openness, price and wage flexibility, a risk sharing system such as fiscal transfer mechanism, and financial integration, then it is an Optimal Currency Area where it would be optimal to create a currency union instead of keeping floating exchange rates.
} 
synchronization of economies. Empirical results are not uniform, though several support the argument of increased synchronization through trade. However, these results are challenged by the view that business cycles in Europe are affected by many factors, which are mostly ignored except the trade channel (Rose, 2008). Exclusion of such factors, such as capital flows or higher sectoral specialization, can lead to potentially biased results.

Another inadequacy of most existing studies is that they are panel analyses examining output co-movements while controlling for currency union impact. Among these, few also address the endogeneity issue with trade by using methods with instrumental variables. However, convergence is a process that takes place over an extended period, disrupted by crises and recessions, speeding up during recovery and booms. Panel analyses are neither sufficiently long enough nor suitable to capture such non-linear processes.

Our paper investigates output growth convergence among several European economies during the period 1975 to 2013 from an angle different than the existing literature. We exploit the time series characteristics of several economies in the European Union, and examine if output growth in the peripheral countries converged towards that of the core countries. Such convergence can be captured directly through the change in the parameter associated with growth in the core countries: the higher the value of the parameter, the greater the synchronization between the core and the periphery.

Business cycle synchronization in this context is defined as a significant correlation between the center and the periphery. We define as integration an increasing correlation over time between output growth rates of the center and the periphery. According to these definitions, integration can also be labeled as increased synchronization.

The term periphery in the public jargon came to represent countries with worrying public finances and recently those with a looming threat of an exit from the union. Unlike the popular terminology, we define periphery as smaller economies in the EU, which may or may not have been subject to market or political pressures to leave the union. We also use data from nonEurozone as a control group.

In our model each peripheral country's output growth is affected by its past performance, its neighboring countries, and the center economies of the Eurozone and the rest of the world. By directly estimating the impact of "center" output on "peripheral" output and controlling for 
endogenous breaks, we are able to detect any possible change that may occur in the estimates not only between the center and the peripherals but also within and outside the Eurozone.

Structural changes happen when the conventional relations between economic variables change as a result of major changes due to factors including globalization, change in the economic political system, important policy shifts, such as adoption of the common currency, economic reforms/policies, recessions and financial crises. The impact of a structural change, such as a single currency on the peripheral's economy, may be observed either after the formation of the currency union or even before the adoption of the single currency as the economies adjust to brace for the currency union. The structural change is endogenous when it is depicted by the data and not imposed by the investigator.

This impact may show up in one of the following patterns: (i) an endogenous break around the time of the euro adoption and further integration of the center and peripherals' outputs after 1999; (ii) no abrupt break around the time of the euro adoption but instead countryspecific breaks throughout the sample, and a gradual and nonlinear integration of the center and peripheral's output growth, reflecting a deliberate economic integration policy initiated by the European countries for over half a century. Our methodology is, therefore, able to establish whether one of these two patterns has characterized synchronization in peripheral countries' business cycles with that of the core and if so, how the model parameters have evolved over time following structural breaks.

Our analysis contributes to the literature in two ways. First, by controlling for multiple endogenous changes in the integration parameter (the impact of core's output growth on peripheral's growth), we analyze if and how the estimated breakpoints are associated with known shocks, including the creation of the single currency. However, due to bilateral trade links the output of the trade partners may enter into a country's output model as an endogenous regressor, which may lead to biased estimates of the parameters and of the break dates. Therefore, our second contribution to the literature is to control for the endogeneity problem by adopting a methodology that allows instrumenting the output of the trade partners. This is an innovative way of tackling the endogeneity problems in the business cycle synchronization literature. Our approach is superior in terms of break location accuracy to the alternative time-varying parameter-based approach as we explain below. 
Our study reaches several interesting findings. First, we identify multiple endogenous break dates that correspond to major shocks in international arena and to idiosyncratic shocks affecting individual countries, suggesting that the convergence process has been nonlinear for a number of countries. In line with the approach adopted by the literature, our result indicates that studies imposing break dates exogenously, such as the launch of euro, may lead to biased conclusions (see Christiano, 1992 and subsequent literature on endogenous break tests). Second, integration (or increased synchronization) occurred in several but not all cases, and when it happened it was as a result of a long process, which accelerated after the 1990s for most countries. Our analysis thus supports the view that the move towards a monetary union likely spurred synchronization among some countries in the region well before the introduction of the euro and continued after that. Third, the non-euro countries' output growth is also significantly impacted by the center. Although it can be argued that these results are not surprising among countries with significant trade ties, as demonstrated in the literature, what is surprising is the lack of increased synchronization among some Eurozone economies despite the existence of such ties and a common currency.

\section{Literature survey}

Several concepts have been used to measure trends in economic activity. To put our definition into perspective an overview is useful. We can group the approaches in two broad categories. Business cycle synchronization and growth convergence. The concept of convergence (or catching-up) describes the hypothesis that poorer economies' income grows faster than rich economies and eventually catches up with the latter. Researchers typically examine the cross-sectional relationship between the growth rate of output per capita over some time period and the initial level of per capita output. $\beta$-convergence occurs when partial correlation between growth in income over time and its initial level is negative (Barro and Sala-iMartin, 1992; Mankiw et al., 1992). $\sigma$-convergence occurs when the dispersion of real income across a group of economies declines over time (Young et al., 2008).

The second approach, which is of interest to us, examines the business cycle, i.e. the movement of economic activity over time and is analyzed as classical cycle or growth cycle. The approach examining the cycles around peaks and troughs are classical business cycles focusing on fluctuations of aggregate economic activity, its absolute decline or rise (Burns and 
Mitchell, 1946). The growth cycle evaluates the cyclical component of GDP (or industrial production) around its underlying long-term trend (Lucas, 1977). In more recent periods the emphasis shifted to absolute changes in GDP, i.e. to classical cycles for two reasons: (i) recessions (absolute declines in activity) became more pronounced relative to trend; (ii) trending methods have been criticized because different methods may give different growth cycles or induce spurious correlations (Canova, 1998). The approach we adopt is more in line with the classical cycle analysis where we examine bilateral growth rates and assess convergence of business cycles.

Business cycle synchronization and growth convergence were major concerns prior to euro's existence because it imposed a one-size-fits-all monetary policy on Eurozone economies with different sizes and structures. The popular argument among European policy makers that higher trade volume generated by a single currency would enhance business cycle synchronization, and therefore lead to convergence, is not theoretically well grounded. Standard Ricardian or Hecksher-Ohlin models suggest that industry specialization increases trade but as Krugman (1993) shows, greater industry specialization by country can lead to more asymmetric responses to industry-specific shocks and hence to business cycle divergence. However, if the shocks are common demand shocks or most trades are intra-industry related, business cycles may become more similar across countries as trade increases (Frankel and Rose, 1998; Shin and Wang, 2003). Thus, the effect of trade on business cycle synchronization may go in either direction.

Empirical literature on EU convergence has taken two directions. The first one assesses the existence of convergence and business cycle synchronization of the Eurozone economies and the second identifies the determinants of business cycle synchronization. In the first case, the literature is far from reaching consensus. Skepticism about convergence and/or synchronization started before the European Monetary Union (Bayoumi and Eichengreen, 1992; Dickerson et al. 1998). Although poorer European countries' growth rates were catching up in the second half of the 1990s, and business cycles getting synchronized among the core countries, the failure of the convergence with the periphery after the financial crisis is frequently documented. Despite some studies that reach an optimistic conclusion (Crespo-Cuaresmo et al. 2008; Lee and Mercurelli, 2014), most of the recent literature points to no or a decline in convergence and even to divergence among some European countries and the new members (Artis et al. 2004; Camacho 
et al., 2008; Giannone et al., 2009; Papageorgiou et al., 2010; Konstantakopoulou and Tsionas, 2011; Lehwald, 2013; Campos and Macchiarelli, 2016; Miles and Vijverberg, 2018). The financial crisis further increased the desynchronization of the periphery from the core (Kaitilia, 2014; Ferroni and Klaus, 2015; Bekiros et al. 2015; Belke et al. 2017; Grigoras and Stanciu, 2016). It is pointed out that the observed convergence among the core is reached at the cost of divergence with the periphery.

The second line of the literature examines the factors affecting convergence, and in particular the nexus of trade and currency union. The initial findings of significant relation have been questioned by empirical research. In a seminal study, Frankel and Rose (1996) indicate that joining a currency union greatly increases trade. The initial estimates of the impact of a common currency on trade suggested a currency union would triple trade between nations sharing the same money (Rose, 2000). Later studies found these estimates to be much smaller (Glick and Rose, 2002; Barr et al., 2003; Micco et al., 2003; Bun and Klaassen, 2007).

Although earlier evidence is more robust on the relation between trade volume and business cycle synchronization, there are notable exceptions. By using thirty years of data for twenty industrialized countries, Frankel and Rose (1998) document empirically that nations with closer trade links tend to have more tightly correlated business cycles. The meta-analysis of Rose (2008) shows that several studies support a significantly positive linkage between trade and business cycles. Yet some studies find an insignificant one. Among these, Alesina, Barro and Tenreyo (2002) conclude that currency unions do raise trade, but do not generally have a significant impact on output co-movement. Barro and Tenreyro (2007) find that although currency unions enhance trade, they actually decrease the co-movement of output.

Several studies analyze additional factors that may drive business cycle synchronization under a common currency such as financial and monetary integration, fiscal convergence, structural reforms and shocks to the economy. For instance, if currency union formation leads to a sharp increase in foreign borrowing (Eichengreen and Hausmann, 1999), peripheral nations' growth may increase much faster as capital flows from center countries to peripheral nations with higher returns. This process, which actually occurred in smaller Eurozone countries in the early years of the euro's existence, would tend to lower, rather than raise output co-movements.

Fiscal convergence, or its lack, is another factor that can be the driving force behind economic convergence or divergence. Bertarelli et al. (2014) suggest that fiscal discipline in the 
1990s led to a speedy convergence of deficit/GDP ratio followed by a noticeable convergence in total government expenditure and total revenue after the introduction of the euro. On the other hand, Censolo and Colombo (2016) document divergence of fiscal aggregates between the periphery and the core after the crisis, which might have been behind desynchronization of their business cycles. A related channel is sovereign debt crisis. According to Lane (2012), the global financial shock had a strong asymmetric impact among the euro area countries. Those with the greatest dependence on international short-term debt markets were the ones who were most negatively affected. As a result of the sovereign debt crisis some countries, such as Greece, Ireland and Portugal, were disproportionally affected by the crisis since they were shut out of the bond market. This type of shocks substantially decreases the co-movement of output.

After a major domestic or global crisis, several countries also embarked on structural reforms such as product market reform, education and tax reforms as we shall see below. Using an endogenous growth model to evaluate the growth impacts of structural reforms Varga, et. al. (2014) show that these reforms induce substantial economic gains in small countries such as Greece, Italy, Spain and Portugal in the medium and long run, which would increase synchronization with their larger economies. De Haan et al. (2008) provide an extensive review of the earlier studies examining the factors driving business cycle synchronization in Europe and conclude that there is no consensus about which factors are the most significant and their effects on convergence.

However, most of the existing studies in the literature examine the comovements of output gap measures with respect to a reference over a period where convergence was expected to occur and they don't examine the dynamic adjustment process - and its inherent nonlinearities - towards this state of nature. Only a handful of studies use nonlinear methods to examine the synchronization question in Europe: A major non-linear approach to business cycle synchronization uses Markov-switching models where the state of the economy (expansion and contraction regimes) is treated as an unobserved latent variable and where state-dependent probabilities of co-movements in cycles are assessed. Di Giorgio (2016) investigates the correlations between the cyclical fluctuations of Central and Eastern European countries and the euro area over the period 1993 to 2014. Estimating the endogenous turning points between regimes, the author shows that the likelihood of business cycle synchronization is quite high in the recession regime, but lower in the normal and high growth regimes. Miles and Vijverberg 
(2018) find that in the eight Eurozone countries analyzed, synchronization increased after the launch of the euro only in one while it decreased in three others.

As an alternative approach to business cycle synchronization, number of authors estimate dynamic factor models using Bayesian methods to identify the synchronization process of country fluctuations with respect to the common factor. Ferroni and Klaus (2015) find that the main driver of France, Germany and Italy is the common Euro Area factor, which makes these countries interdependent. Lee (2013) finds that both output growth and inflation tended to be more synchronized among European countries during the run-up to the EMU, but there is no strong evidence to support the argument that the 'regional' effects of the euro area prevailed after 1999. Identifying a common Euro factor for each of the pre-euro period and euro period, Lehwald (2013) shows that business cycle synchronization rose for the core Eurozone countries and respectively declined for the periphery. De Lucas Santos and Delgado Rodríguez (2016) show that there is positive correlation of the national business cycles with the common European core business cycle.

A large strand of the literature argues that the usual focus on co-movements and correlations can be misleading since national cycles can exhibit large differences in their amplitudes despite strong correlations between them. Nonparametric local polynomial regressions are used to calculate correlation indices and thus prevent making priors about the functional form of the time evolution of business cycle synchronization. Over the period after the financial crisis, Belke et al (2017) find increased synchronization between core countries and decreased synchronization of the peripheral countries (see above). Pointing out the importance of the frequency domain beside the usual time domain in comparing cycles, Bekiros et al (2015) use a wavelet approach to detect and identify the scale-dependent time-varying synchronization (or not) between the Eurozone and the non-Eurozone area business cycles before and after the financial crisis.

Other studies examine the synchronization process by assessing time-varying correlations between countries and the core in a nonlinear multivariate framework. Using Riskmetrics and Scalar-BEKK models, Degiannakis et al (2014) examine how the instantaneous correlation level between the individual business cycles of $14 \mathrm{EU}$ countries and the aggregate EU12 business cycle varies over time. They find that business cycle synchronization until 2007 has been 
followed by a desynchronization of many periphery countries' business cycles with EU12 after the Eurozone crisis.

Finally, there are concerns about the approaches adopted in the literature to measure the business cycle synchronization. In the early cross-country literature, some studies use the correlation of either stock market returns or the cyclical components of output levels across countries as a way to evaluate the international integration (Eichengreen, 2001). Later studies estimate the correlations with moving windows over different time periods with instrumental variables (Barro and Tenreyro, 2007; Rose, 2008). Mink et al. (2012) criticize such use of correlations. They argue that a perfectly correlated output gap may still imply a large discrepancy in synchronization because of large differences in cyclical amplitudes. They show that the alternative measures output gap "synchronicity" (similarity of signs) and "similarity" (similarity of output gaps) do not necessarily coincide with the traditional measures of output gap correlation. Belke et. al. (2017) also emphasize the importance of examining cyclical amplitudes in analyzing synchronization. By dividing all countries into different clusters, they find that countries belonging to the core were faced with increased synchronization among themselves after 2007Q4, but peripheral countries' synchronization with the core, non-EMU countries and among themselves diminished.

Unlike the previous studies, we propose to evaluate the evolution of the business cycle from an endogenous multiple structural change perspective. Our study emphasizes the interaction between the breaks in the integration parameter and the synchronization of the growth rates among the Eurozone economies. These breakpoints in the data provide useful information for understanding the internal or external forces that drive synchronization. .

Our approach is in line with Sander and Kleimeier (2004) who test the convergence in the Eurozone retail banking, another strand of the literature examining convergence. The study examines the change of pass-through of interest rates to test if the monetary transmission process in Eurozone is uniform between 1993 and 2002. For this, the authors search for a unique endogenous break; they find that the structural breaks in the transmission mechanism do not coincide with the introduction of euro; rather, the breaks occurred much earlier. Marotta (2009) extends their analysis by allowing for multiple structural breaks; the pattern of the structural break dates indicates that national banking systems adjust slowly to the new monetary regime. He thus cautions the association of structural changes to the introduction of euro. 


\section{Model and Methodology}

We estimate the following model for each peripheral country in our sample (Austria, Belgium, Denmark, Finland, Greece, Ireland, Netherlands, Portugal, Spain and Sweden):

$$
\Delta y_{t}=\alpha+\beta \Delta y_{t}^{F G}+\delta \Delta y_{t}^{N}+\gamma \Delta y_{t}^{U S}+\sum_{i} \omega_{i} \Delta y_{t-i}+\varepsilon_{t}
$$

where $\Delta y_{t}, \Delta y_{t}^{N}, \Delta y_{t}^{F G}$ and $\Delta y_{t}^{U S}$ stand for, respectively, change in the output of the peripheral country or the small economy, change in the weighted average output of the three largest trade partners (neighbors) of the peripheral country, change in the weighted average output of the core Germany-France and change in the U.S. output. The notion of "neighbor" here implies economic neighbors rather than geographical neighbors. We calculate $y_{t}^{F G}$ as a weighted average of the output of Germany and that of France. Since our goal is to assess the impact of the core on the peripheral countries, we control for $\Delta y_{t}^{F G}$ separately by excluding it from the calculation of $\Delta y_{t}^{N}$. We should note that for economic and historic reasons our core definition includes only France and Germany, the two largest economies in Europe. We exclude Italy from the core because it has been usually associated with the "periphery" yet it is too large to be part of it. Lagged dependent variables are introduced until the first insignificant lag is reached in order to remove possible residual autocorrelation.

Equation (1) shows that growth in a given peripheral country is affected by growth in the core, its neighbors and the United States, and its own past performance. Our goal is to assess $\beta$, the integration parameter with the core, which measures the extent to which a peripheral country's business cycle co-moves with that of the core. We estimate this parameter controlling for the impact of the business cycle in the trading partners as well as the rest of the world, represented by the US economy. Let $\left(\beta_{1}, \delta_{1}, \gamma_{1}\right)$ and $\left(\beta_{2}, \delta_{2}, \gamma_{2}\right)$ represent values of the parameters $(\beta, \delta, \gamma)$ before and after a structural break, say the adoption of the Euro, respectively. We hypothesize that there is an increased synchronization with the core if $\beta_{1} \geq 0$, $\beta_{2}>0$ and $\beta_{2}>\beta_{1}$ and a decreased synchronization if $\beta_{2}<\beta_{1}$. In the case of $\beta_{1}=\beta_{2}$, synchronization with the core remains constant. 
However, this is a very restrictive and unrealistic condition since countries have followed a long process of conversion towards monetary unification and did not switch their economies overnight when they become members of the union. To capture this process, we adopt the less restrictive hypothesis of gradual convergence, which will be reflected in several estimates due to multiple breaks. Reforms or policies in a peripheral country or the ECB's macroeconomic initiatives may affect the integration parameter anytime during the period under consideration. If such shocks exist, ignoring them would bias the results and give misleading estimates, especially for $\beta$. Since the top trade partners of the periphery often include countries that are part of the EU but not the monetary union (such as UK, Sweden and Denmark), a significant and positive $\delta$ also indicates a larger regional integration that is likely due to the existence of the single market, which increased the volume of trade among all members.

$\Delta y_{t}^{N}$ is potentially an endogenous regressor. This arises when two countries are among the largest three partners of each other. Then the output growth of a country A depends on a major trade partner B's output growth through $\Delta y_{t}^{N}$, while country A appears simultaneously as a major trade partner for country B in another equation similar to (1). Such endogeneities can cause simultaneity biases that are known to yield inconsistent estimates. As we will show below, in our panel of peripheral countries an important subset consists of mutual major partners and therefore subject to the endogeneity problem. The remaining countries are not concerned by this problem.

Since our goal is to check for the instability of the parameters in equation (1) in order to assess whether the core Germany-France has impacted the growth of peripheral economies, we implement Bai and Perron's (1998) (BP) methodology of estimation with endogenous structural breakpoints for those countries for which all the regressors are exogenous. If there is a Eurozone influence, we expect to find instability in parameters in the form of an increasing value of $\beta$ over our sample period. To account for possible endogenous structural breaks, we rewrite model (1) as:

$$
\Delta y_{t}=\sum_{j=1}^{m+1} \theta_{j}^{\prime} \quad z_{t} 1_{t \in I}+v_{t}
$$


where $z_{t}=\left(1, \Delta y_{t}^{F G}, \Delta y_{t}^{N}, \Delta y_{t}^{U S}\right)^{\prime}, \theta=\left(\alpha, \beta, \delta, \gamma, \omega_{1}, \omega_{2}, \ldots\right)^{\prime}, m$ is the unknown number of breaks, $I_{j}(j=1, \ldots, m+1)$ the segment between break dates $t_{j-1}$ and $t_{j}$ and $1_{t \in I}$ an indicator function such that $1_{t \in I}=1$ for $t_{j-1}<t \leq t_{j}$ and 0 elsewhere $\left(t_{0}=1\right.$ and $\left.t_{m+1}=T\right)$. The vector of coefficients $\theta_{j}$ characterizes the effects of the exogenous variables $z_{t}$ on $\Delta y_{t}$ over the $j$ th segment $(j=1, \ldots, m+1) .^{2}$ A break date $\hat{t}_{j}$ is estimated as $\arg \min _{1 \leq t_{j} \leq T} \operatorname{SSR}\left(t_{j}\right)$, where $\operatorname{SSR}$ is the sum of squared residuals over the sample. Using a sequential F-test procedure, $m$ is determined when the null of $m$ breaks against $m+1$ breaks is not rejected. When no break occurs $(m=0)$, the coefficient vector $\theta$ is estimated over the full sample and model (2) collapses to model (1).

However, when the model contains endogenous regressors, the OLS-based BP method cannot be used. Hall et al (2012) (HHB) extend BP's methodology to linear models with endogenous regressors within an instrumental variables (IV) framework, which provides consistent estimators of parameters in the presence of endogenous regressors. The idea is to conduct explicit breakpoint analyses for both the endogenous regressors and the structural model containing these regressors using the 2SLS method. To the best of our knowledge, no previous study has tested endogenous changes in business cycle synchronization by controlling for endogeneity of regressors, although models describing output growth interdependence often involve such feedback effects. ${ }^{3}$

For each country, we select appropriate instruments for the endogenous regressor $\Delta y_{t}^{N}$ such that they are correlated with the latter and orthogonal to $\varepsilon_{t}$. We consider the following as instruments: the lagged variables $\Delta y_{t-i}^{N}, i=1,2 \ldots$, the actual and lagged values of the changes in the outputs of Germany $\Delta y_{t-i}^{G}$, of France $\Delta y_{t-i}^{F}$ and of USA $\Delta y_{t-i}^{U S}, i=0,1 \ldots$ This IV regression

\footnotetext{
${ }^{2}$ The partial structural change model introduced by BP also includes a second vector of independent variables whose parameters are not subject to shifts. We allow all parameters to adjust to the breaks, given that they may prove to be insignificantly different between subsequent segments if they are genuinely constant over the period.

${ }^{3}$ Even though this model has some resemblance to a spatial panel model, this approach would be inadequate to achieve our goal since a spatial panel model with endogenous breaks has not yet been developed. Furthermore, in a spatial panel model, the "spatial correlation" parameter before the "spatial weight" matrix is the same for all countries involved. Thus, given the same "spatial correlation" parameter, the neighboring countries may impact other peripheral countries differently only through the pre-assigned spatial weights. Our model in this paper does not impose this kind of pre-assigned restrictions.
} 
equation is called the Reduced form (RF), whereas model (1) is labeled as the Structural form (SF).

The test procedure suggested by HHB can be summarized by the following two steps. First, test for the presence of structural breaks in the RF using the sequential BP methodology. Second, (a) If there is no break in the RF, test for the presence of structural breaks in the SF using the BP methodology. (b) If the null of no break is rejected in the RF, test for the presence of structural breaks in the SF using the BP methodology over each sub-period determined by the estimated breaks in the RF. Then, check whether the breaks identified in the RF coincide with additional ones in the SF by performing Wald tests over the appropriate sub-samples evidenced by the estimated breaks in the SF.

A popular approach in describing the change in the integration parameter is to assume that this parameter evolves following a dynamic stochastic model. This parameter equation, together with the peripheral country's growth equation, can be represented as a state-space model and estimated using Kalman filtering. However, with this approach, when the change in the parameter is mild and gradual, it may not be easy to locate in the sample the date at which the change is significant by visual inspection. Yet, identifying such points in time is important to understanding the specific historical events causing the instability in the parameter (e.g., macroeconomic policies, political changes, international shocks). The endogenous nature of convergence towards synchronization necessitates a data-driven identification of the specific events at play. This is in line with Frankel and Rose (1998), who state that cyclical correlation between economies depends on trade integration, which itself is affected by European Union (EU) policies. Rather than a model with continuously time-varying parameters, we thus need to specify a model where movements in the output growth correlation between peripheral countries and the core can be addressed through discrete changes at unknown dates resulting from idiosyncratic or global shocks. This can be achieved by using our methodology, which is superior to alternative methods in terms of breakpoint location accuracy.

It is worth noting that such discrete changes do not mean that convergence occurs with abrupt changes. They, instead, indicate that among the very large number of small breaks that shape the parameter dynamics over a given segment of time, none can be diagnosed as being significant, provided that any significant change initiates a new segment. Thus, the integration parameter is statistically constant over a segment but it changes from one segment to another. 
Since the (unknown) number of breakpoints is not set a priori but is endogenously determined by using a sequential test procedure, the identification of all the significant breakpoints ensures parameter stability over each sub-period.

\section{Data}

Our data consist of monthly industrial production index (IP) from OECD to represent each country's output, spanning from January 1975 to June 2013. Our choice of IP to proxy for GDP is motivated by the concern of the large number of observations required to conduct the endogenous break tests. Given the rise in the share of the services in GDP, the use of IP can be problematic. To see whether this is an issue, we checked the correlation between IP and PPPadjusted GDP for each economy. Our results show a significant and large correlation coefficient of $90 \%$ or more between the two series for all countries except in Greece, where it is somewhat lower (Table 1).

Since our focus is on the peripheral countries, our investigation will focus mainly on representative small economies within the Eurozone: Austria, Belgium, Finland, Greece, Ireland, Netherlands, Portugal, and Spain. Among these, Portugal, Ireland, Greece and Spain, are also designated as PIGS since the European debt crisis. We added two non-Eurozone small economies, Denmark and Sweden, both part of the EU but not the Eurozone, as a control group to see how the economies that do not adhere to a common currency behaved over the same sample. We chose these two countries because they have different currency regimes. Denmark decided not to adopt the euro to preserve their economic sovereignty but the Krone was shadowing the DM and then the euro. Sweden rejected the adoption of the euro in a referendum in 2003 and kept its currency the Swedish krona, floating. Note that Austria, Belgium, Finland, Ireland, Netherlands, Portugal and Spain joined the Eurozone in January 1999; Greece was admitted to join in January 2001.

The weights are obtained by computing for each period the ratio of each country's trade to total trade of both countries, denominated in U.S. dollars. We compute $y_{t}^{N}$, the output of major trade partners (economic neighbors), by taking the trade-weighted average of the peripheral neighbors' outputs. The trade weights are obtained based on the US-dollar values of imports and exports with respect to its trading partners from 1990 to 2011. We compute the trade weights by 
using the OECD data. For each country, we calculate the average of both imports and exports over the years of 1990-2011, the last available data. Based on this data, there are 33 trade partners for each country. After excluding Germany, France and non-EU countries, we select three of those with the highest average total trades as the dominant trade partners of each country. We obtain the respective weight of these three countries by calculating the ratio of the average total trade of each country to the sum of the average total trades of the three countries. In general, for most countries in this study, the selected three trade partners constitute about a third of each country's total trade. When we add the United States, France and Germany, which we control in the equation, we are able to capture majority of the trade activity for individual countries.

\section{Empirical Results}

Out of ten countries, four do not have an endogeneity problem in the independent variables. For these four countries, Austria, Finland, Greece and Ireland, we apply the BP methodology of endogenous multiple structural breaks with exogenous regressors (Tables 2 and 3). For the remaining six countries for which endogeneity was an issue (Belgium, Denmark, Netherlands, Portugal, Spain and Sweden) we use the HHB instrumental variables methodology to test for breaks and estimate the model (Tables 4 and 5). For sake of simplicity, we will refer to the countries in Tables 2 and 3 as group 1 and to those in Tables 4 and 5 as group 2 .

In both Table 2 and Table 4, the test is a sequential test of the null of $k$ breaks against the alternative of $k+1$ breaks, $k=0,1,2 \ldots$ The null is rejected in favor of the alternative if the minimal value of the overall sum of squared residuals for the $k+1$ break model is smaller than the one for the $k$ break model. The double maximum statistics $U D \max F_{T}$ and $W D \max F_{T}$ test the null of no structural change against an unknown number of breaks up to some upper-bound $M$. They are referred to as double maximum because under the alternative hypothesis the maximization involves the choice for the number of breaks $m=1, \ldots, M$ and for the selection of the highest $F$ statistic for a given value of $m$. However, BP note that the supF test for $m$ breaks may be of low power if $m$ is large and suggest to apply appropriate weights to these individual statistics. This gives the weighted double maximum statistic $W D \max F_{T}$, while $U D \max F_{T}$ is its unweighted version. Finally, a significant break implying significant changes in the structural parameters of the model across the two adjacent sub-periods, it is natural to allow error variances to change 
across regimes rather than imposing homogenous error variances, which is a restrictive assumption. We then conduct these tests by allowing for regime-specific error distributions, which includes the particular case of homogeneity, if appropriate.

\section{Endogenous break dates}

According to whether the regressor $\Delta y_{t}^{N}$ is exogenous or endogenous, BP and HHB multiple structural break tests have shown the presence of two breakpoints for Belgium, a single breakpoint for Austria, Finland, Greece, Portugal, Spain and Sweden and no break for Ireland, Denmark and Netherlands (Tables 1 and 3). The double maximum statistics indicate that among group 1 countries there is a parameter shift at the 5\% level for Austria, Finland and Greece while the sequential $F$ test rejects the null of 0 break in favor of 1 break but fails to reject the null of 1 break in favor of 2 breaks. The break points for these three countries are March 1991, October 1989, and April 2007, respectively. These three dates are associated with major shocks in the global arena as well as idiosyncratic shocks to individual countries. For Ireland none of the test results supports the presence of a break. It is important to note that any structural change in parameter indicates a major economic event such as a reform, a crisis or an economic policy. However, all economic events do not necessarily lead to a change in the parameter of the model. If, indeed, a major event affects the dependent and the independent variables simultaneously, the slope coefficients may not change significantly.

In Table 2, the break date of March 1991 in Austria is a typical domestic shock-induced breakpoint in that it corresponds to the beginning of the recession that followed a high growth period. In the early 1990s, recession reduced the growth rate from 4.2 percent in 1990 down to 0.4 percent in 1994. The last decade of the 1990s are also characterized by the liberalization inspired by the EU. A process of privatization of state-owned enterprises took place throughout this period. The break of 1989 October in Finland also is marked by a recession period that started in 1990. Throughout the 1980s, financial deregulation consisting of removal of controls on bank borrowing and foreign borrowing, together with a fixed currency but appreciating real exchange rate culminated in a financial bubble at the end of the decade. The collapse of the Soviet Union in 1991 is widely considered to be the last drop in the cup that triggered the Finnish recession, often called a depression worse than that of the 1930s. It reduced the volume of trade 
by $2 / 3$ and forced the monetary authority to devalue. Explosion of foreign currency denominated debt as a result of devaluation and new emphasis on bank regulation precipitated the burst of the bubble. The decade following the break date was marked by a profound restructuring in the Finnish financial sector triggered by the banking crisis.

In Greece, the last country of group 1, the breakpoint occurs at the beginning of the 20072008 financial crisis when the economy entered its protracted recession. The breakpoint at 2007 seems to be at odds with the well-known fact that the global financial shock had a very strong impact on Greece at 2010. As Lane (2012) mentions, Greece had debt/GDP ratio over 90 percent since the early 1990s and sovereign debt level was elevated around 2007. Also, during the 2003-2007 period, Greece was running very large current account deficits. The breakpoint of 2007 appears to be a precursor announcing the travails of the Greek economy and marks the beginning of a protracted recession in the economy. In 2009, Greece revealed that its budget deficit was $12.7 \%$ of its GDP, which was higher than EU's 3\% limit. That shocked the investors and caused its government bond yield to rise sharply. Thus, in May 2010, Greece was shut out of the bond market and the EU/IMF provided bailout package in return for austerity measures. The crisis deteriorated as deleveraging took place, which led to a deep recession.

As for Ireland, due to low interest rates and low corporate tax rates, the country experienced a major real estate and commercial development in the $2000 \mathrm{~s}^{4}$. In 2006 , the economy relied heavily on construction industry, which made up 25\% of Ireland's GDP and employed $20 \%$ of its work force. When financial crisis occurred in 2008, real estate market in Ireland crashed. The country went into recession for the first time since 1980s. The unemployment rate went up considerably. As the government deficit became an issue, Ireland had to receive an 85 billion euro bailout from IMF and ECB with a government's promise to implement subsequent structural reforms and fiscal austerity. The following deleveraging slowed down growth considerably. Ireland was one of the most negatively affected countries because it was totally shut out of the bond market around November 2010 (Lane, 2012).

In the second group, Belgium exhibits one break in August 1982 that affects the reduced form. In the structural form, we find one break at the left of this break date and another at the right of this break date, which gives the two break dates September 1980 and February 1995.

\footnotetext{
${ }^{4}$ Honohan, P. (2009) "What Went Wrong with Ireland", manuscript prepared for the Word Bank, Trinity College Dublin.
} 
However, the Wald test result indicates that the structural form does not support the break date of the reduced form. For Belgium, therefore, we retain the two break dates in 1980 and 1995. The breakpoint of September 1980 corresponds to the beginning of the first of a series of recessions in the country triggered by the oil crises of the 1970s. The recession of the 1980-1982 was a severe one with large unemployment and deficit, which reached 13\% of GDP. The crisis led to a major restructuring of the economy when activity moved from Wallonia to Flanders. Belgium is an advanced industrial economy with a relatively stable average quarterly growth rate of 0.53 percent between 1980 and 2014. The notable exception of an all-time high of 15.80 percent in the first quarter of 1995 was fueled by a sharp rise in gross fixed investment and government spending. The second breakpoint of February 1995 is consistent with this idiosyncratic high growth rate, which followed a severe recession in 1992-93. This date also corresponds to a period of fiscal consolidation that the country embarked on with a view of EMU membership that required evidence of declining GDP share of public debt following the Maastricht criteria. As a result of these policies, Belgium successfully achieved a decline in its debt/GDP ratio.

In Denmark and the Netherlands, we detect one break in the reduced form (Table 4, top panel), respectively. However, evidence does not support any break in the structural form conditional to the breaks in the reduced form (Table 4, bottom panel). Therefore, for these two countries no break point is retained.

By contrast, for Portugal and Spain, no break appears in the reduced form (top panel). We, therefore, test for multiple breaks in the structural form over the whole sample. Test results reject the null and find breaks in January 2004 in Portugal and June 1992 in Spain (bottom panel). The Portuguese economy grew at a healthy average rate of 3 percent in the run up to the adoption of the euro. However, during the 2000s it went through a recession and anemic growth, the lowest in Europe, while its competitors were expanding. Portugal's breakpoint of January 2004 corresponds to the end of the recession but the beginning of a dismal growth period. This can be attributed to a decline in productivity throughout the slump period starting 2000, caused by misallocation of capital flows to unproductive subsectors of nontradables (Reis, 2013). The current account imbalance for Portugal was small during 1993-1997, but, by 2003-2007, Portugal was running very large external deficits, as pointed out by Lane (2012). Thus, the breakpoint of 2004 was not at odds with the literature. 
Spain's break coincides with many domestic and international factors. These include the European financial crisis in the summer of 1992, three times devaluation of its currency between 1992 and 1993 and an economic downturn in the early 1990s that lasted till mid-1990s, after which it returned to a vigorous growth spurred by strong foreign investment before entering the European Monetary Union in 1999. This break data also corresponds to the first stage of the housing price bubble that characterized the Spanish economic growth for the next two decades. The housing price increase may be divided into 3 stages: $^{5}$ 1985-1991 (price tripled); 1992-1996 (price remained stable); 1996-2008 (price increased substantially). The housing bubble led to booming property investments and strong construction sectors, which induced unsustainable GDP growth. The Spanish Great Recession started in 2008, triggered mainly by the burst of the housing bubble that led to a sharp decline in construction and the actual housing sales which went down by $25 \%$. The earlier property boom fueled debt accumulation, but also generated extra tax revenues in both Spain and Ireland (Lane, 2012). However, both Ireland and Spain failed to use these extra revenues to improve fiscal positions. The end of the credit boom and the decline in construction were major shocks to the Spanish economy. Due to high sensitivity of tax revenues to a decline in the construction sector and asset prices, tax revenues dropped and the deficit/GDP ratio rose sharply. In June 2012, Spain requested international aid package for its banks, which were crippled by bad real estate debt after the burst of the housing bubble.

In our sample, Sweden is the only country where a break of February 1982 found in the reduced form is significantly supported by the Wald test. No additional break is detected in this equation on either side of the break date obtained from the reduced form. This break date falls in the middle of a major restructuring effort that Sweden took up during the 1980s to escape the 1970s' slow growth rates. During this period, which was also called Sweden's "lost decade", output growth decreased from one of the highest in Europe to one of the lowest. During the early 1980s policy makers launched a series of deregulations in many sectors including government and financial markets, devaluing the Swedish krona by 24 percent and cutting back the deficit. By 1984 these measures started slowly to invigorate economic activity through domestic investment, although growth did not reach its healthy levels until the early 1990s.

Our results lend further support to the argument that exogenously imposed break dates can be quite misleading and lead to biased estimates. It is striking that adoption of a single

\footnotetext{
${ }^{5}$ See references in https://en.wikipedia.org/wiki/Spanish_property_bubble
} 
currency in 1999 did not create any instability in the regression results. In all economies that exhibit instability in the parameters of equation (1), the break points correspond to dates when the countries experienced an economic recession, slowdown or a demand shock. By inspecting the changes in the parameter estimates, we can examine whether there was any integration and if so, when it started.

\section{Parameter estimates}

From the estimated parameters across regimes reported in Tables 3 and 5, it can be seen that our parameter of interest, $\beta$, although positive in general, comes in with a magnitude and significance that vary among the economies. It becomes more significant after the break in some economies, doesn't change for some and remains insignificant for two countries. This suggests an asymmetric synchronization with the center. Interestingly, our results do not support the notion that specific dates of major policy changes, such as the switch to euro in 1999, triggered a closer integration between the peripherals and the core in euro zone. Synchronization did occur in several cases but it was a result of a long process, which accelerated after the 1990s for some countries.

Among the first group of countries with one break the estimates of the integration parameter $\beta$ are positive but not significant in the pre-break period (Table 4, top panel, first 3 columns). But for Austria and Greece, the estimates of $\beta$ become significant and larger after their respective breaks, suggesting an increased synchronization to the core. It is interesting to note that at no point in the data Finland exhibits any integration to the core both before and after the breakpoint. In Ireland the integration estimate is positive and significant at the 10 percent confidence level throughout the sample period without any structural breakpoint.

The estimates of the parameters $\delta$ and $\gamma$ show the measure of integration with the European trade partners' economies and the US economy, respectively. Inspection of $\delta$ shows a higher level of business cycle synchronization after the break points in Austria and Finland with their European partners, but a similar synchronization happens before the breakpoint in Greece. The United States acquires significance as a trade partner only in Finland after the break point. The Irish economy is also affected not only by its European neighbors but especially by the US.

Among the second group of countries, the estimate of the integration parameter is similarly insignificant before the respective breaks of Portugal and Spain (Table 5). Portugal has 
become more synchronized with the core after the breakpoint in 2004 while Spain remains uncorrelated with the core after the break of 1992 in line with Miles and Vijverberg (2018). Both countries' economic activities are highly correlated with those of their neighbors (these are UK, Italy and Portugal for Spain and UK; Italy and Spain for Portugal). In Belgium, the only economy with two breaks, the estimate of the integration parameters is weakly significant in the first subsample, during the period of accelerating European integration. The convergence seems to be adversely affected by the series of recessions that the country went through during the 1980s, but it picks up speed after the second break, which also corresponds to the start of the Schengen agreements in 1995. Except during the first subsample, the Belgian economic activity is not synchronized with its neighbors (Netherlands, UK, Italy). The last country in this group, the Netherlands, has no break and a strong and positive integration parameter indicating a synchronized economic activity with the center, and a strong and significant synchronization with the US but none with its neighbors (Belgium, UK, Italy).

When we consider the results of the PIGS two points need to be stressed. First, the stronger synchronization of Greece with the core after 2007 is simply due to the country's recession coinciding with the slowdown in the core and therefore, not a reliable indication that the economy strongly integrated to the core. Second, Ireland's integration parameter estimate is weakly significant, while Spain never shows any significant convergence. These facts suggest that results do not support unequivocally the hypothesis of gradual synchronization for three out of four PIGS economies.

It is interesting to note that economic activity in the two non-euro countries, Sweden and Denmark, does not display a particularly different behavior compared to that of the euro countries. Denmark, which does not have a break, exhibits a strong synchronization with the center but an insignificant one with its neighbors (Sweden, UK and the Netherlands) and none with the US. After the break, Sweden's output correlation with the center becomes significant and positive and its economic ties with the US strengthen considerably. This result suggests that even if they do not belong to the Eurozone, the Netherlands from the beginning and Sweden after its break became candidates to the European currency union.

At first glance, it may be surprising to see such disparity between the three Nordic countries, Finland, Denmark and Sweden since these economies share several common characteristics such as comparable size and population, sharing a common Nordic labor market 
and accomplishing financial liberalization around the same time during the 1980s. Despite these similarities, they also differ from each other. ${ }^{6}$ Under the pressure of deeper European integration, when all three countries liberalized their financial markets, they also experienced financial market bubbles. At the end of the 1980s with the onset of the international recession the bubbles burst. Economic conditions worsened further as a result of the European financial crisis of the 1991-92. But Denmark was the least affected since its liberalization process started much earlier, its financial markets were deeper and its economy better integrated with the rest of Europe. After a costly World War II that left the economy poorer than its Nordic counterparts, Finland's economy was more integrated with the Soviet Union and its financial markets shallower. ${ }^{7}$ These conditions made the impact of global shocks much harsher on its economy. After 1992 Finland joined the European Monetary System, Denmark continued shadowing the DM, and Sweden floated its currency. These different trajectories explain at least partly the disparity observed in our results.

To sum up, although most of the estimates of the integration parameters are not significant before the break, some, but not all, become significant after the country-specific break dates. Thus, Austria, Belgium, and Portugal indicate an increased integration with the core after their respective endogenous breaks; Netherlands and Ireland have a non-increasing, stable integration with the core from the beginning. Spain doesn't show any integration before or after the break point. Among the two non-Eurozone economies, Denmark was all along integrated with the core, while Sweden became integrated after the break. Finally, regarding the two opposing views of the "trade" implication mentioned in the introduction, i.e., the view that a common currency increases trade, which improves synchronization, versus the view that higher trade integration brings in specialization and asymmetric shocks and eventually reduces synchronization, our analysis suggests that some economies' experience supports the first view while others are consistent with the second view.

\footnotetext{
${ }^{6}$ For a comprehensive review of the economic conditions in the 1980s in the Nordic countries see Honkapohja (2012)

7 Some commentators also point to the "Nokia" effect, describing the dominance of a single company in an economy. Between 1998 and 2007 Nokia's share in the Finnish economic growth was 25\% and contributed a similar amount to exports. Its decline facing competition from Apple hurt considerably the growth prospects of the economy. The Finnish economy's dependence on global conditions due to this effect may be one factor that accounts for Finland's lack of convergence with the core towards the end of our sample.
} 


\section{Robustness check}

In a recent article, Perron and Yamamoto (2015) (PY) show that, in the presence of endogenous regressors, it is preferable to estimate directly the break dates of the structural model by simply using the OLS-based BP method, and then perform an IV regression to estimate the parameters conditional on the estimated breaks. The main argument of PY is that in the IV methodology of HHB, the regressors generated as a projection of the original regressors on the space spanned by the instruments have less quadratic variation than the original regressors involved by OLS, making the break point estimates less accurate. However, HHB argue that neglected endogeneity in regressors in the PY method may still continue to contaminate OLS-based estimations of breaks in the structural equation and yield inconsistent OLS estimators of parameters in the sub-periods. Moreover, 2SLS is still needed in PY's approach, making it not different than HHB's method regarding parameter estimation (Chen, 2015). For these reasons we followed the HHB technique but also report the results with the PY methodology so as to compare the outcomes from the two approaches.

The PY approach consists in (a) estimating the breaks in the SF by using the OLS-based BP method and (b) estimating, using an IV regression, the parameters of the SF within each subperiod determined by the break dates obtained using the OLS-based procedure. Our findings for the second group of countries using the HHB's 2SLS procedure compare to those evidenced by performing the PY's sequential OLS followed by sample-based IV approach (see Table 1A, Appendix). For this last stage of PY procedure, we used the same instruments as those used for the HHB method.

Interestingly, despite different methodologies for identifying the breaks, both approaches lead to similar results. One exception is Belgium, for which the PY method depicted one break at February 1995 (instead of the two breaks estimated previously, see Table 3), this single break being identical to the second break estimated using the HHB procedure. Conversely, in the case of Portugal the breakpoint and consequently the estimates within the adjacent subperiods are totally identical for both methods (the standard deviations are slightly different though, but not such as to alter the significance of the corresponding estimates). As with the HHB method, PY's approach did not lead to find any break for Denmark and Netherlands, leading therefore to the same full-sample estimates. For Spain and Sweden, estimated breaks are October 1991 and December 1985, respectively, according to the PY method. These dates compare to the break 
dates June 1992 and February 1982 obtained with our approach using HHB. Although for each country the break dates from the two approaches do not coincide, the difference is small enough to make the estimates insignificantly different from one approach to the other (only one standarddeviation confidence interval of an estimate according to one method includes the corresponding estimated value according to the other method). Overall, our results using the HHB's 2SLS procedure are supported by PY's OLS-IV method. ${ }^{8}$

\section{Conclusion}

In this study we examine the economic growth synchronization characteristics of several small or peripheral countries in the European Union with core countries. We analyze whether the process towards monetary union and the common experience of a single currency led to increased integration of output growth for these member countries with the core economies. To test for synchronization, we use a methodology that accounts for endogenous structural breaks, nonlinearities and endogeneity problem in the regressors when reverse causality arises between a country and its trading partners. To our knowledge, this approach has never been applied before in this literature.

Our results indicate the following. First, in all economies that exhibit instability in the parameters, breaks occurred when the countries experienced an economic recession, slowdown or a demand shock, concurrently with an ongoing process of economic and financial integration efforts. Our results lend further support to the argument that exogenously imposed break dates

\footnotetext{
${ }^{8}$ We also checked using a panel structural test whether our countries share one or more common breaks and, if so, if these breaks coincide with the launch of the Euro. We considered both our panel of 10 countries and a panel restricted to the Eurozone countries only, leaving thus aside Denmark and Sweden. For each panel, we first considered the demeaned transformation of all of our variables $\Delta y_{t}, \Delta y_{t}^{N}, \Delta y_{t}^{F G}$ and $\Delta y_{t}^{U S A}$ for each country so as to remove the fixed effect (the "within transformation"). We then stacked in order these transformed variables to test for the presence of common breakpoints using pooled least squares. We finally applied Equation (2) to our pooled data. As our goal was to check whether one of the common breakpoints coincides with the launch of the Euro, we stopped searching additional breaks once divergent locations were obtained. This procedure helped us identify three breakpoints for each panel of countries. These are, in order of increasing full-sample-SSR, March 1997, May 2009 and October 2010 for our 10-countries panel and June 1992, May 2009 and August 2012 for the Eurozone countries panel. These results call for two remarks. First, none of the estimated breaks falls in the neighborhood of the Euro adoption, implying that the advent of the Euro cannot be considered as a common structural break. Secondly, none of the panel breakpoints coincide with country-specific breaks (except June 1992 when Spain was specially hit by the Exchange rate mechanism crisis). These discrepancies between individual and panel breaks are due to the existence of significant slope heterogeneity between countries (Tables 3 and 5), which is not compatible with the panel data approach that assumes that major events have common impact on every periphery economy.
} 
corresponding to crises or specific institutional changes in the system can be quite misleading and lead to biased estimates.

Second, for several peripheral Eurozone countries the parameter of synchronization is either constant at all times or becomes significant after their respective breaks. Our results thus suggest that the process towards monetary union has led to an asymmetric pattern of synchronization of growth rates. It helped increase synchronization of some countries' growth, albeit gradually. These countries were in a long convergence process in anticipation of their membership in the monetary union, which strengthened subsequently after they joined the union. For others, synchronization did not change over time and remained constant. For two countries, Spain and Finland, monetary union did not lead to any synchronization with the core. These economies became more integrated with their European partners excluding the core, and/or the US economy.

Third, we also observe a strong integration with the core of two countries outside the Eurozone. This result suggests that adoption of a single currency also likely increased economic integration in the whole region and led to similar patterns of economic growth in the nonEurozone countries of our sample.

Our analysis thus shows that there is no common endogenous structural break associated with global shocks nor by the institutional adoption of the common currency. In the path to integration of small EU economies, domestic-induced economic shocks are as important as global financial shocks and their impact is felt at different points in time. As for the degree of integration with the core, the results also vary with different countries. Even though entering the EMU is likely to enhance trade and increase the small economies' access to more mature capital markets by achieving integration, this cannot be taken for granted. A country's own economic and financial management is an important element in the process of integration. 


\section{Appendix}

Table 1A Estimation of models with endogenous regressors (Perron-Yamamoto)

\begin{tabular}{|c|c|c|c|c|c|c|}
\hline & Belgium & Denmark & Netherlands & Portugal & Spain & Sweden \\
\hline $\begin{array}{l}\text { 1st sub- } \\
\text { period }\end{array}$ & $\begin{array}{l}1975.02 \\
1995.01[240]\end{array}$ & $\begin{array}{l}1975.02 \\
2013.06[461]\end{array}$ & $\begin{array}{l}1975.02 \\
2013.06[461]\end{array}$ & $\begin{array}{l}1975.02 \\
2003.12[347]\end{array}$ & $\begin{array}{l}1975.02 \\
1991.09[200]\end{array}$ & $\begin{array}{l}1975.02 \\
1985.11[130]\end{array}$ \\
\hline$\alpha_{1}$ & $\begin{array}{l}0.001 \\
(0.67)\end{array}$ & - & - & $\begin{array}{l}0.01 * * * \\
(4.14)\end{array}$ & - & - \\
\hline$\beta_{1}$ & $\begin{array}{l}0.21 * \\
(1.93)\end{array}$ & $\begin{array}{l}0.43^{* * * *} \\
(3.49)\end{array}$ & $\begin{array}{l}0.35 * * * \\
(3.34)\end{array}$ & $\begin{array}{l}0.12 \\
(1.08)\end{array}$ & $\begin{array}{l}0.18 \\
(0.79)\end{array}$ & $\begin{array}{l}0.12 \\
(0.59)\end{array}$ \\
\hline$\delta_{1}$ & $\begin{array}{l}-0.21 \\
(-1.11)\end{array}$ & $\begin{array}{l}0.11 \\
(0.49)\end{array}$ & $\begin{array}{l}-0.08 \\
(-0.34)\end{array}$ & $\begin{array}{l}0.38 * * \\
(2.32)\end{array}$ & $\begin{array}{l}0.04 \\
(0.96)\end{array}$ & $\begin{array}{l}-0.42 \\
(-0.99)\end{array}$ \\
\hline$\gamma_{1}$ & $\begin{array}{l}0.28 \\
(1.51)\end{array}$ & $\begin{array}{l}0.25 \\
(1.18)\end{array}$ & $\begin{array}{l}0.37 * * * \\
(2.34)\end{array}$ & $\begin{array}{l}-0.18 \\
(-0.88)\end{array}$ & $\begin{array}{l}0.17 \\
(0.52)\end{array}$ & $\begin{array}{l}0.77 * * \\
(2.45)\end{array}$ \\
\hline $\begin{array}{l}2 \mathrm{~d} \text { sub- } \\
\text { period }\end{array}$ & $\begin{array}{l}1995.02 \\
2013.06[221]\end{array}$ & & & $\begin{array}{l}2004.01- \\
2013.06[114]\end{array}$ & $\begin{array}{l}1991.10 \\
2013.06[261]\end{array}$ & $\begin{array}{l}1985.12 \\
2013.06[331]\end{array}$ \\
\hline$\alpha_{2}$ & $\begin{array}{l}0.002 * * \\
(2.24)\end{array}$ & & & $\begin{array}{l}-0.005^{* *} \\
(-2.40)\end{array}$ & - & - \\
\hline$\beta_{2}$ & $\begin{array}{l}0.57 * * * \\
(5.60)\end{array}$ & & & $\begin{array}{l}0.67 * * * \\
(4.15)\end{array}$ & $\begin{array}{l}-0.23 \\
(-1.54)\end{array}$ & $\begin{array}{l}0.39 * * * \\
(3.79)\end{array}$ \\
\hline$\delta_{2}$ & $\begin{array}{l}-0.21 \\
(-1.17)\end{array}$ & & & $\begin{array}{l}0.57 * \\
(1.96)\end{array}$ & $\begin{array}{l}2.47 * * * \\
(4.33)\end{array}$ & $\begin{array}{l}0.07 \\
(0.42)\end{array}$ \\
\hline$\gamma_{2}$ & $\begin{array}{l}0.04 \\
(0.29)\end{array}$ & & & $\begin{array}{l}-0.19 \\
(-0.73)\end{array}$ & $\begin{array}{l}-0.17 \\
(-1.00)\end{array}$ & $\begin{array}{l}0.54 * * * \\
(3.51)\end{array}$ \\
\hline
\end{tabular}

Notes. Numbers in parentheses are t-values. Subscript $i=1,2$ attached to parameters denote the $i$ th sub-period. $* * * * *$ and

* represent 1, 5 and $10 \%$ levels of significance, respectively. When intercepts where insignificant they have been removed from the model before reestimation. Dates in italics are the significant breakpoints at the $5 \%$ level. 


\section{References}

Alesina, A., R. Barro, and S. Tenreyro (2002), "Optimal Currency Areas," in NBER Macroeconomics Annual 2002, 17, 301-356.

Artis, M., H.M. Krotzig, and J. Toro (2004), "The European Business Cycle," Oxford Economic Papers, $56(1), 1-44$.

Bai, J., and P. Perron (1998), "Estimating and Testing Linear Models with Multiple Structural Changes," Econometrica, 66(1), 47-78.

Barr, D., F. Breedon, and D. Miles (2003)," Life on the Outside: Economic Conditions and Prospects outside Euroland," Economic Policy, 37, 573-613.

Barro, R., and S. Tenreyro (2007), "Economic Effects of Currency Unions," Economic Inquiry, 45, 1-23.

Barro, R., and X. Sala-i-Martin (1992), “Convergence,” Journal of Political Economy, 100(2), 223-251.

Bayoumi, T. and Eichengreen, B. (1992), "Shocking Aspects of European Monetary Unification," NBER Working Paper, no. 3949.

Bekiros, S., D.K. Nguyen, G. Salah Uddin, and B. Sjö (2015), "Business Cycle (de)synchronization in the Aftermath of the Global Financial Crisis: Implications for the Euro Area," Studies in Nonlinear Dynamics and Econometrics, 19(5), 609-624.

Belke, A., C. Domnick, and D. Gros (2017), "Business Cycle Synchronization in the EMU: Core vs. Periphery," Open Economies Review, 28(5), 863-92.

Bertarelli, S., R. Censolo, and C. Colombo (2014), "Fiscal Convergence in the European Union before the Crisis," Contemporary Economic Policy, 32 (4), 784-801.

Burns, A., and W. Mitchell (1946), "Measuring Business Cycles,” NBER Book Series, New York.

Bun, M., and F. Klaassen (2007), "The Euro Effect on Trade is not as Large as Commonly Thought," Oxford Bulletin of Economics and Statistics, 69(4), 473-496.

Camacho, M., G. Perez Quiros and L. Saiz (2008), "Do European Business Cycles Look Like One?" Journal of Economic Dynamics and Control, 32, 2165-90.

Campos, N.F., and C. Macchiarelli (2016), "Core and Periphery in the European Monetary Union: Bayoumi and Eichengreen 25 years later," Economics Letters, 147, 127-130.

Canova, F. (1998), “Detrending and Business Cycle Facts” Journal of Monetary Economics, 41, 475-512.

Censolo, R., and C. Colombo (2016), "The Impact of the Crisis on Fiscal Convergence in the EU: The Early Signs," Journal of European Integration, 38(6), 703-717. 
Chen, B. (2015) "Modeling and Testing Smooth Structural Changes with Endogenous Regressors," Journal of Econometrics, 185, 186-215.

Crespo Cuaresmo, J., D. Ritzberger-Grunwald, and M.A. Silgoner (2008), "Growth, Convergence and EU Membership," Applied Economics, 40(5), 643-56.

Christiano, L.J. (1992), "Searching for a Break in GNP" Journal of Business and Economic Statistics, 10(3), 237-50.

De Haan, J., R. Inklaar, and R . Jong-A-Pin (2008), "Will Business Cycles in the Euro Area Converge? A Critical Survey of Empirical Research,” Journal of Economic Surveys, 22(2), 234-273.

De Lucas Santos, S., and M.J. Delgado Rodríguez (2016), "Core-Periphery Business Cycle Synchronization in Europe and the Great Recession," Eastern European Economics, 54, 521-546.

Degiannakis, S., D. Duffy, and G. Filis (2014), "Business Cycle Synchronization in E.U.: A Time-varying Approach," Scottish Journal of Political Economy, 61(4), 348-370.

Di Giorgio, C. (2016), "Business Cycle Synchronization of CEECs with the Euro Area: A Regime Switching Approach," Journal of Common Market Studies, 54(2), 284-300.

Dickerson, A., H. Gibson, and E. Tsakalotos (1998), "Business Cycle Correspondence in the European Union," Empirica, 25(1), 49-75.

Eichengreen, B. (2001), "Capital Account Liberalization: What do the Cross-Country Studies Tell Us?" World Bank Economic Review, 15(3), 341-65.

Eichengreen, B., and R. Hausmann (1999), "Exchange Rates and Financial Fragility," Proceedings, Federal Reserve Bank of Kansas City, 329-368.

Ferroni, F., and B. Klaus (2015), "Euro Area Business Cycles in Turbulent Times: Convergence or Decoupling?" Applied Economics, 47(34-35), 3791-3815.

Frankel, J., and A. Rose (1996), "Economic Structure and the Decision to Adopt a Common Currency," Seminar Papers 611, Stockholm University, Institute for International Economic Studies.

Frankel, J., and A. Rose (1998), "The Endogeneity of the Optimum Currency Criteria," Economic Journal, 108, 1009-1025.

Giannone, D., M. Lenza, and L. Reichlin (2009), "Business Cycles in The Euro Area," European Central Bank WP Series No.1010.

Glick, R., and A. Rose (2002), "Does a Currency Union Affect Trade? The Time Series Evidence." European Economic Review, 46, 1125-1151.

Grigoras, V., and I.E. Stanciu (2016), "New Evidence on the (de)Synchronisation of Business Cycles: Reshaping the European Business Cycle," International Economics, 147, $27-52$.

Hall, A., S. Han, and O. Boldea (2012), "Inference Regarding Multiple Structural Changes in Linear Models with Endogenous Regressors," Journal of Econometrics, 170, 281-302. 
Honkapohja, S. (2012), “The 1980s Financial Liberalization in the Nordic Countries," Bank of Finland Research DP 36.2012.

Kaitilia, V. (2014), "Income Convergence and National income disparity: Europe, 1960-2012," Journal of Economic Integration, 29(2), 343-371.

Kenen, P.B. (1969), “The Theory of Optimum Currency Areas : An Eclectic View," in Mundell, R.A. and Swoboda, A.K. (eds): Monetary problems of the International Economy, University of Chicago Press, 4160.

Konstantakopoulou, I., and E. Tsionas (2011), "The Business Cycle in Eurozone Economies (1960 to 2009)," Applied Financial Economics, 21(20), 1495-1513.

Krugman, P. (1993), "The Narrow and Broad Arguments for Free Trade," American Economic Review, Papers and Proceedings of the $105^{\text {th }}$ Annual Meeting of the American Economic Association, 83(2), 36266.

Lane, P. (2012), "The European Sovereign Debt Crisis," The Journal of Economic Perspectives, 26(3), Summer, 49-68.

Lee, J. (2013), "Business Cycle Synchronization in Europe: Evidence from a Dynamic Factor Model," International Economic Journal, 27, No. 3, 347-364.

Lee, K.-S, and Mercurelli, F. (2014), "Convergence in the Core Eurozone under the Global Financial Crisis," Journal of Economic Integration, 29(1), 20-63.

Lehwald, S. (2013), "Has the Euro Changed Business Cycle Synchronization? Evidence from the Core and the Periphery," Empirica, 40(4), 655-684.

Lucas, R.E. (1977), "Understanding Business Cycles,” Carnegie_Rochester Conference Series on Public Policy, 5, 7-29.

Mankiw, N. G., D. Romer, and D.N. Weil (1992), "A contribution to the Empirics of Economic Growth," Quarterly Journal of Economics, 107(2), p407-437.

McKinnon, R.I. (1963), “Optimum Currency Areas,” American Economic Review, 53(4), 717-725.

Marotta, G. (2009), "Structural Breaks in the Lending Interest Rate Pass-through and the Euro," Economic Modelling, 26(1), 191-205.

Micco, A., E. Stein, and G. Ordonez (2003) "The Currency Union Effect on Trade: Early Evidence from EMU”, Economic Policy ,37, 315-356.

Miles, W., and C-P C. Vijverberg (2018), "Did the Euro Common Currency Increase or Decrease Business Cycle Synchronization for its Member Countries?", Economica, 85(339), 558-580.

Mink, M., J. Jacobs, and J. de Haan (2012), "Measuring Coherence of Output Gaps with an Application to the Euro Area," Oxford Economic Papers, 64(2), 217-236. 
Mundell, R. (1961), “A Theory of Optimum Currency Areas,” American Economic Review, 51(4), 657665 .

Papageorgiou, T., P.G. Michaelides, and J.G.Milios (2010), "Business cycles synchronization and clustering in Europe (1960-2009)," Journal of Economics and Business, 62(5), 419-470.

Perron, P., and Y. Yamamoto (2015), "Using OLS to Estimate and Test for Structural Changes in Models with Endogenous Regressors," Journal of Applied Econometrics, 30(1), 119-144.

Reis, R. (2013), “The Portuguese Slump and Crash and the Euro crisis," Brookings Papers on Economic Activity, 1, 143-193.

Rose, A. (2000), "One Money, One Market, the Effect of Common Currencies on Trade," Economic Policy, 15, 7-46.

Rose, A. (2008), "Is EMU Becoming an Optimum Currency Area? The Evidence on Trade and Business Cycle Synchronization," Unpublished manuscript, http://faculty.haas.berkeley.edu/arose/EMUMetaECB.pdf

Sander, H., and Kleimeier, S. (2004), "Convergence in the Euro-Zone Retail Banking? What Interest Rate Pass-through Tells Us About Monetary Policy Transmission, Competition and Integration," Journal of International Money and Finance, 23, 461-492.

Shin, K., and Wang Y. (2003), "Trade Integration and Business Cycle Synchronization in East Asia," Asian Economic Papers. MIT Press 2(3), 1-20.

Varga, J., W. Roeger and J. Veld (2014), "Growth Effects of Structural Reforms in Southern Europe: the Case of Greece, Italy, Spain and Portugal," Empirica, 41, 323-363.

Young, A, M. Higgins and D. Levy (2008), "Sigma Convergence Versus Beta Convergence: Evidence from U.S. County-level Data," Journal of Money, Credit and Banking, 40(5), 1083-93. 
Table 1. Correlation coefficients between the PPP-adjusted GDP and IP for each country

\begin{tabular}{ll}
\hline Austria & 0.99 \\
Belgium & 0.95 \\
Denmark & 0.96 \\
Finland & 0.99 \\
France-Germany & 0.96 \\
Greece & 0.77 \\
Ireland & 0.99 \\
Netherlands & 0.99 \\
Portugal & 0.91 \\
Spain & 0.87 \\
Sweden & 0.95 \\
U.S.A. & 0.99 \\
\hline Source: Authors'calculations
\end{tabular}




\section{Table 2. Multiple break tests with exogenous regressors (Bai-Perron)}

\begin{tabular}{lllll}
\hline $\mathrm{c}$ & Austria & Finland & Greece & Ireland \\
\hline$U D \max F_{T}$ & $23.51(1)^{* *}$ & $28.56(1)^{* *}$ & $32.04(1)^{* *}$ & $17.13(3)$ \\
& & & \\
$W D \max F_{T}$ & $23.51(1)^{* *}$ & $28.56(1)^{* *}$ & $32.04(1)^{* *}$ & $22.22(5)$ \\
& $23.51(1 / 0)^{* *}$ & $28.56(1 / 0)^{* *}$ & $32.04(1 / 0)^{* *}$ & $11.48(1 / 0)$ \\
$\operatorname{Sup}_{T}(k+1 / k)$ & $5.74(2 / 1)$ & $19.71(2 / 1)$ & $22.33(2 / 1)$ & \\
\hline$\hat{t}_{S F}$ & 1991.03 & 1989.10 & 2007.04 & - \\
\hline$\hat{t}_{S F}$ denotes the & estimated break & in the structural form. $U D \max F_{T}, W D \max F_{T}$ and
\end{tabular}

$\operatorname{SupF}_{T}(k+1 / k)$ are the unweighted and weighted double maximum statistics reached at the indicated number of breaks and the sequential $F$-statistic for the null of $k$ break(s) versus $k+1$ break(s), respectively. ** represents 5\% level of significance. Critical values at the $5 \%$ level for $U D \max F_{T}, W D \max F_{T}, \operatorname{Sup} F_{T}(1 / 0)$, $\operatorname{SupF}_{T}(2 / 1)$ are 20.30, 21.86, 20.8, 22.11 for Austria, 22.04, 23.81, 21.87, 24.17 for Finland, 23.87, 25.63, 23.70, 25.75 for Greece and 23.87, 25.63, 23.70 for Ireland. A trimming percentage of 15\% is employed and error distributions are allowed to differ across breaks. 
Table 3. Estimation of models with exogenous regressors (Bai-Perron)

\begin{tabular}{|c|c|c|c|c|}
\hline & Austria & Finland & Greece & Ireland \\
\hline & $\begin{array}{l}1979.02-1991.02 \\
{[145]}\end{array}$ & $\begin{array}{ll}1975.02 & -1989.09 \\
{[176]} & \end{array}$ & $\begin{array}{l}1975.02-2007.03 \\
{[386]}\end{array}$ & $\begin{array}{l}1975.12-2013.06 \\
{[451]}\end{array}$ \\
\hline$\alpha_{1}$ & $\begin{array}{l}0.005^{* * *} \\
(3.41)\end{array}$ & $\begin{array}{l}0.007 * * * \\
(3.08)\end{array}$ & $\begin{array}{l}0.003 * * \\
(2.38)\end{array}$ & $\begin{array}{l}0.01 * * * \\
(5.04)\end{array}$ \\
\hline$\beta_{1}$ & $\begin{array}{l}0.02 \\
(0.14)\end{array}$ & $\begin{array}{l}0.15 \\
(1.07)\end{array}$ & $\begin{array}{l}0.04 \\
(0.40)\end{array}$ & $\begin{array}{l}0.26^{*} \\
(1.72)\end{array}$ \\
\hline$\delta_{1}$ & $\begin{array}{l}0.10 \\
(1.45)\end{array}$ & $\begin{array}{l}0.20 \\
(1.57)\end{array}$ & $\begin{array}{l}0.15^{*} \\
(1.65)\end{array}$ & $\begin{array}{l}0.28 * \\
(1.67)\end{array}$ \\
\hline \multirow[t]{2}{*}{$\gamma_{1}$} & $\begin{array}{l}0.20 \\
(1.02)\end{array}$ & $\begin{array}{l}-0.30 \\
(-1.13)\end{array}$ & $\begin{array}{l}0.14 \\
(0.74)\end{array}$ & $\begin{array}{l}0.62 * * \\
(2.33)\end{array}$ \\
\hline & $\begin{array}{l}1991.03-2013.06 \\
{[268]}\end{array}$ & $\begin{array}{l}1989.10-2013.06 \\
{[285]}\end{array}$ & $\begin{array}{l}2007.04-2013.06 \\
{[75]}\end{array}$ & \\
\hline$\alpha_{2}$ & $\begin{array}{l}0.004 * * * \\
(3.46)\end{array}$ & $\begin{array}{l}0.001 \\
(0.70)\end{array}$ & $\begin{array}{l}-0.01 * * * \\
(-3.39)\end{array}$ & \\
\hline$\beta_{2}$ & $\begin{array}{l}0.40 * * * \\
(4.34)\end{array}$ & $\begin{array}{l}0.18 \\
(1.54)\end{array}$ & $\begin{array}{l}0.72 * * * \\
(3.30)\end{array}$ & \\
\hline$\delta_{2}$ & $\begin{array}{l}0.15 * * \\
(2.19)\end{array}$ & $\begin{array}{l}0.33 * * * \\
(2.84)\end{array}$ & $\begin{array}{l}-0.18 \\
(-0.68)\end{array}$ & \\
\hline$\gamma_{2}$ & $\begin{array}{l}0.004 \\
(0.02)\end{array}$ & $\begin{array}{l}0.66^{* * * *} \\
(3.25)\end{array}$ & $\begin{array}{l}-0.18 \\
(-0.54)\end{array}$ & \\
\hline $\bar{R}^{2}$ & 0.30 & 0.20 & 0.31 & 0.29 \\
\hline
\end{tabular}

Notes. Numbers in parentheses are t-values. Subscript $i=1,2$ attached to parameters denote the $i$ th sub-period. $* * *, * *$ and $*$ represent 1,5 and $10 \%$ levels of significance, respectively. Dates in italics are the significant breakpoints at the $5 \%$ level as reported in Table 2 . 
Table 4. Multiple break tests with endogenous regressors (Hall-Han-Boldea)

\begin{tabular}{|c|c|c|c|c|c|c|}
\hline & Belgium & Denmark & Netherlands & Portugal & Spain & Sweden \\
\hline \multicolumn{7}{|c|}{ Break test in the IV- reduced form of $\Delta y_{t}^{N P}$} \\
\hline$U D \max F_{T}$ & $25.23(1)^{* *}$ & $31.52(1)^{* *}$ & $20.07(2)^{* *}$ & $15.08(3)$ & $12.95(1)$ & $27.95(1)^{* *}$ \\
\hline$W D \max F_{T}$ & $25.23(1)^{* *}$ & $31.52(1)^{* *}$ & $23.60(2)^{* *}$ & $20.89(5)$ & $18.58(5)$ & $27.95(1)^{* *}$ \\
\hline $\operatorname{SupF}_{T}(k+1 / k)$ & $25.23(1 / 0)^{* *}$ & $31.52(1 / 0)^{* *}$ & $18.56(1 / 0)^{* *}$ & $9.20(1 / 0)$ & $12.95(1 / 0)$ & $27.95(1 / 0)^{* *}$ \\
\hline & $12.11(2 / 1)$ & $12.71(2 / 1)$ & $11.45(2 / 1)$ & - & - & $7.92(2 / 1)$ \\
\hline$\hat{t}_{R F}$ & 1982.08 & 1978.01 & 2005.11 & - & - & 1982.02 \\
\hline \multicolumn{7}{|c|}{ Break test in the structural form over the sub-periods conditional on $\hat{t}_{R F}$} \\
\hline$U D \max F_{T}(\mathrm{~L})$ & $27.60(1)^{* *}$ & (a) & $19.44(1)$ & $31.28(1)^{* *}$ & $24.92(1)^{* *}$ & $25.49(2)^{* *}$ \\
\hline$W D \max F_{T}(\mathrm{~L})$ & $27.60(1)^{* *}$ & (a) & $20.16(3)$ & $31.28(1)^{* *}$ & $24.92(1)^{* *}$ & $30.53(3)^{* *}$ \\
\hline$U D \max F_{T}(\mathrm{R})$ & $44.64(1)^{* *}$ & $16.86(1)$ & $20.94(2)$ & & & $22.08(2)^{* *}$ \\
\hline$W D \max F_{T}(\mathrm{R})$ & $44.64(1)^{* *}$ & $16.86(1)$ & $29.00(5)^{* *}$ & & & $25.52(2)^{* *}$ \\
\hline $\operatorname{Sup}_{T}(k+1 / k)(\mathrm{L})$ & $27.60(1 / 0)^{* *}$ & (a) & $19.44(1 / 0)$ & $31.28(1 / 0)^{* *}$ & $24.92(1 / 0)^{* *}$ & $13.98(1 / 0)$ \\
\hline \multirow{3}{*}{$\operatorname{SupF}_{T}(k+1 / k)(\mathrm{R})$} & $9.52(2 / 1)$ & & & $11.10(2 / 1)$ & $12.96(2 / 1)$ & \\
\hline & $44.64(1 / 0)^{* *}$ & $16.86(1 / 0)$ & $11.90(1 / 0)$ & & & $19.35(1 / 0)$ \\
\hline & $7.42(2 / 1)$ & & & & & \\
\hline$\hat{t}_{S F}(\mathrm{~L})$ & 1980.09 & (a) & - & 2004.01 & 1992.06 & - \\
\hline$\hat{t}_{S F}(\mathrm{R})$ & 1995.02 & - & - & & & - \\
\hline \multicolumn{7}{|c|}{ Wald test for the presence of the break $\hat{t}_{R F}$ in the structural form } \\
\hline \multirow{2}{*}{$\begin{array}{l}\text { Wald p-value } \\
\text { Sub-sample }\end{array}$} & 0.07 & 0.75 & 0.06 & - & - & 0.0001 \\
\hline & $\begin{array}{r}1980.09- \\
1995.01\end{array}$ & $\begin{array}{r}1975.02- \\
2013.06\end{array}$ & $\begin{array}{r}1975.02- \\
2013.06\end{array}$ & - & - & $\begin{array}{r}1975.02- \\
2013.06\end{array}$ \\
\hline
\end{tabular}

Notes. $\hat{t}_{R F}$ and $\hat{t}_{S F}$ denote the estimated breaks in the reduced and structural forms, respectively. UDmax $F T, W D \max F T$ and $\operatorname{SupFT}(k+1 / k)$ are the unweighted and weighted double maximum statistics reached at the indicated number of breaks and the sequential $F$-statistic for the null of $k$ break(s) versus $k+1$ break(s), respectively. (L) and (R) associated with the statistics or breaks in the second panel indicate that these are determined over the subsamples at the left or at the right of $t R^{n} F$. Statistics or breaks with (L) solely are assessed over the full sample. ** represents 5\% level of significance. Critical values at the 5\% level for (UDmaxFT, WDmaxFT, SupFT(1/0),SupFT(2/1)), in the case of the reduced form and of the structural form are $(16.37,17.83,16.19,18.11)$ and (20.30, 21.86, 20.08, 22.11) for Belgium, $(23.87,25.63,23.70,25.75)$ and $(18.42,19.96,19.23)$ for Denmark, $(16.37,17.83,16.19$, $18.11)$ and $(22.04,23.81,21.87)$ for Netherlands, $(23.87,25.63,23.70)$ and $(22.04,23.81,21.87,24.17)$ for Portugal, $(16.37,17.83$, $16.19)$ and $(18.42,19.96,18.23,19.91)$ for Spain and $(20.30,21.86,20.08,22.11)$ and $(20.30,21.86,20.08)$ for Sweden, respectively. A trimming percentage of $15 \%$ is employed and error distributions are allowed to differ across breaks. (a) indicates that the breakpoint test cannot be performed because of a too short sub-sample ( 35 observations). Dates in italics are the significant breakpoints at the $5 \%$ level. 
Table 5. Estimation of models with endogenous regressors (Hall-Han-Boldea)

\begin{tabular}{|c|c|c|c|c|c|c|}
\hline & Belgium & Denmark & Netherlands & Portugal & Spain & Sweden \\
\hline $\begin{array}{l}\text { 1st sub- } \\
\text { period }\end{array}$ & $\begin{array}{l}1975.02 \\
1980.08[67]\end{array}$ & $\begin{array}{l}1975.02 \\
2013.06[461]\end{array}$ & $\begin{array}{l}1975.02 \\
2013.06\end{array}$ & $\begin{array}{l}1975.02 \\
2003.12[347]\end{array}$ & $\begin{array}{l}1975.02 \\
1992.05[208]\end{array}$ & $\begin{array}{l}1975.02 \\
1982.01[84]\end{array}$ \\
\hline$\alpha_{1}$ & $\begin{array}{l}-0.001 \\
(-0.18)\end{array}$ & - & - & $\begin{array}{l}0.01 * * * \\
(4.12)\end{array}$ & - & - \\
\hline$\beta_{1}$ & $\begin{array}{l}0.40^{*} \\
(1.72)\end{array}$ & $\begin{array}{l}0.42 * * * \\
(3.60)\end{array}$ & $\begin{array}{l}0.35^{* * * *} \\
(3.60)\end{array}$ & $\begin{array}{l}0.12 \\
(1.07)\end{array}$ & $\begin{array}{l}0.20 \\
(0.92)\end{array}$ & $\begin{array}{l}0.38 \\
(1.10)\end{array}$ \\
\hline$\delta_{1}$ & $\begin{array}{l}-0.41 \\
(-0.79)\end{array}$ & $\begin{array}{l}0.14 \\
(1.27)\end{array}$ & $\begin{array}{l}-0.06 \\
-(0.26)\end{array}$ & $\begin{array}{l}0.38^{* *} \\
(2.31)\end{array}$ & $\begin{array}{l}-0.02 \\
(-0.02)\end{array}$ & $\begin{array}{l}-0.76 \\
(-1.28)\end{array}$ \\
\hline$\gamma_{1}$ & $\begin{array}{l}0.81^{* *} \\
(2.13)\end{array}$ & $\begin{array}{l}0.24 \\
(1.16)\end{array}$ & $\begin{array}{l}0.42 * * * \\
(2.65)\end{array}$ & $\begin{array}{l}-0.18 \\
(-0.88)\end{array}$ & $\begin{array}{l}0.15 \\
(0.48)\end{array}$ & $\begin{array}{l}0.79 * \\
(1.74)\end{array}$ \\
\hline $\begin{array}{l}2 \mathrm{~d} \text { sub- } \\
\text { period }\end{array}$ & $\begin{array}{l}1980.09 \\
1995.01[173]\end{array}$ & & & $\begin{array}{l}2004.01- \\
2013.06[114]\end{array}$ & $\begin{array}{l}1992.06 \\
2013.06[253]\end{array}$ & $\begin{array}{l}1982.02 \\
2013.06[377]\end{array}$ \\
\hline$\alpha_{2}$ & $\begin{array}{l}0.002 \\
(1.10)\end{array}$ & & & $\begin{array}{l}-0.005 * * \\
(-2.44)\end{array}$ & - & - \\
\hline$\beta_{2}$ & $\begin{array}{l}0.12 \\
(1.00)\end{array}$ & & & $\begin{array}{l}0.67 * * * \\
(4.22)\end{array}$ & $\begin{array}{l}-0.24 \\
(-1.59)\end{array}$ & $\begin{array}{l}0.21 * * \\
(2.26)\end{array}$ \\
\hline$\delta_{2}$ & $\begin{array}{l}0.03 \\
(0.32)\end{array}$ & & & $\begin{array}{l}0.57 * * \\
(1.99)\end{array}$ & $\begin{array}{l}2.60 * * * \\
(4.49)\end{array}$ & $\begin{array}{l}0.19 \\
(1.23)\end{array}$ \\
\hline$\gamma_{2}$ & $\begin{array}{l}-0.09 \\
(-0.38)\end{array}$ & & & $\begin{array}{l}-0.19 \\
(-0.74)\end{array}$ & $\begin{array}{l}-0.11 \\
(-0.68)\end{array}$ & $\begin{array}{l}0.63 * * * \\
(4.51)\end{array}$ \\
\hline
\end{tabular}

$\begin{array}{ll}\begin{array}{ll}\text { 3d sub- } \\ \text { period }\end{array} & \begin{array}{l}1995.02 \\ 2013.06\end{array} \\ \alpha_{3} & 0.002^{* *} \\ & (2.10) \\ \beta_{3} & 0.54 * * * \\ & (5.30) \\ \delta_{3} & -0.17 \\ & (-0.96) \\ \gamma_{3} & 0.06 \\ & (0.40)\end{array}$

$\begin{array}{lllllll}\bar{R}^{2} & 0.29 & 0.10 & 0.29 & 0.30 & 0.30 & 0.24\end{array}$

Notes. Numbers in parentheses are t-values. Subscript $i=1,2,3$ attached to parameters denote the $i$ 'th sub-period. $* * *, * *$ and $*$ represent 1,5 and $10 \%$ levels of significance, respectively. When intercepts were insignificant they have been removed from the model before reestimation. Dates in italics are the significant breakpoints at the 5\% level as reported in Table 4. 